\title{
Televisão regional no Brasil: uma proposta de sistematização de períodos históricos ${ }^{1}$
}

\author{
José Tarcísio OLIVEIRA FILHO²
}

\begin{abstract}
Resumo:
O artigo propõe-se a uma revisão histórica bibliográfica e documental do telejornalismo regional no Brasil, com foco nos aspectos ligados à mídia televisiva em cada capital brasileira precursora de produção regional/local. Para isso, são sistematizados três momentos históricos: 1) a fase inicial, nas décadas de 1950 e 1960, em que surgem as primeiras tevês locais/regionais e as, então, novas tecnologias de produção e transmissão; 2) o período de ampliação dos telejornais com foco regional, entre as décadas de 1970 e 1990; 3) o cenário contemporâneo, em que são descritos os desafios e as consequências do percurso histórico brasileiro - principalmente devido à predominância do modelo comercial e de grandes grupos econômicos que detém as emissoras locais e regionais.
\end{abstract}

Palavras-chave: TV regional; telejornalismo; jornalismo local; história regional.

\section{Regional TV in Brazil: a systematization proposal of historical periods}

\begin{abstract}
:
The article proposes a historical bibliographic and documental review of regional television journalism in Brazil, focusing on aspects related to television media in each Brazilian capital precursor of regional/local production. For this, three historical moments are systematized: 1) the initial phase, in the decades of 1950s and 1960s, when the first local/regional TVs and new production and transmission technologies appeared; 2) the increase in TV news programs with a regional focus, between the decades of $1970 \mathrm{~s}$ and $1990 \mathrm{~s} ; 3$ ) the contemporary scenario, in which the challenges and consequences of the Brazilian historical path are described - mainly due to the predominance of the commercial model and large economic groups that own local and regional broadcasters.
\end{abstract}

Keywords: regional TV; TV journalism; local journalism; regional.history.

\section{Televisión regional en Brasil: una propuesta para la sistematización de períodos históricos}

Resumen:

El artículo propone una revisión bibliográfica y documental histórica del periodismo televisivo regional en Brasil, centrándose en aspectos relacionados con los medios televisivos en cada capital brasileña precursora de la producción regional / local. Para ello, se sistematizan tres momentos históricos: 1) la fase inicial, en las décadas de 1950 y 1960, cuando aparecieron las primeras televisiones locales / regionales y, luego, las nuevas tecnologías de producción y transmisión; 2) el período de auge de los informativos televisivos con enfoque regional, entre las décadas de1970 y 1990; 3) el escenario contemporáneo, en el que se describen los desafíos y consecuencias de la

\footnotetext{
${ }^{1} \mathrm{O}$ artigo trata-se de uma versão ampliada e revisada da pesquisa apresentada no XXIV Congresso de Ciências da Comunicação da Região Sudeste, em Vitória-ES, em 2019.

${ }^{2}$ Doutor em Comunicação Social pela Universidade Federal de Minas Gerais (UFMG). Professor e pesquisador do Programa de Pós-Graduação em Comunicação da Universidade Federal de Roraima (PPGCOM/UFRR). Email: jose.tarcisio@ufrr.br
} 
trayectoria histórica brasileña, principalmente por el predominio del modelo comercial y de los grandes grupos económicos dueños de las emisoras locales y regionales.

Palabras clave: televisión regional; periodismo televisivo; periodismo local; historia regional.

\section{Introdução}

O telejornalismo local e regional faz parte do cotidiano do brasileiro. Primeiramente, pela própria abrangência do sinal televisivo. A Pesquisa Brasileira de Mídia de 2016 (BRASIL, 2016) demonstra que a televisão é o principal meio de comunicação para o brasileiro se informar, com $63 \%$ das respostas. Parte considerável dos canais e de seus respectivos conteúdos são disponibilizados gratuitamente de Norte a Sul do Brasil, geralmente por meio de emissoras afiliadas de grandes redes comerciais, como é o caso da TV Globo, SBT, RecordTV e Band, além das educativas, comunitárias, públicas e universitárias.

Observa-se que o cenário contemporâneo da televisão no Brasil é, assim como no caso das mídias impressa e radiofônica, reflexo de sua história. Se na Europa as televisões públicas disputam a liderança da audiência em posição de igualdade com as privadas, tanto por uma cultura que compreende a importância da diversidade da mídia e pelas emissoras públicas terem surgido primeiro do que as comerciais, como em Portugal, na Espanha e no Reino Unido (LEAL FILHO, 1997; PICCININ, 2004), no Brasil nota-se um predomínio das emissoras privadas tanto em termos de audiência, como de captação de recursos financeiros. Essa configuração também contribui para o modo de organização das emissoras locais e regionais ${ }^{3}$ (OLIVEIRA FILHO, 2019).

Nessa perspectiva, este artigo propõe-se a elaborar um percurso histórico da mídia televisiva regional no Brasil, com ênfase no telejornalismo, de forma a tensionar alguns pontos críticos. Para isso, são sistematizadas três fases da tevê regional: a de surgimento das tevês regionais (Fase 1); a da popularização de telejornais regionais (Fase 2) e o cenário contemporâneo (Fase 3). Para a proposta, recorre-se à revisão bibliográfica com abordagem dialética-histórica, utilizando como fontes trabalhos científicos, arquivos audiovisuais de domínio público e documentos informativos.

\footnotetext{
${ }^{3}$ Toma-se neste estudo a proposta de classificação de escalas de Aguiar (2016), que define local como recorte espacial que abrange até uma região metropolitana; e regional como sendo desde um aglomerado de pequenas cidades até uma divisão política administrativa.
} 
Fase 1 (1950-1960): as primeiras emissoras e o início das tevês regionais

As duas primeiras décadas da televisão no país foram praticamente protagonizadas pelas emissoras comerciais. ${ }^{4}$ A TV Tupi de São Paulo, pertencente aos Diários Associados de Assis Chateaubriand, foi a pioneira, ${ }^{5}$ sendo sua primeira emissão no dia 18 de setembro de 1950 . Como até então o Brasil não contava com indústrias de televisores, a solução encontrada por Chateaubriand era que se "contrabandeasse 200 receptores e os espalhassem pelos bares e lojas de São Paulo" (BARBOSA, 2013, p. 276). Assim, a tevê, como mídia, nascia "extremamente localizada" do ponto do acesso ao sinal, com alcance limitado a 100 quilômetros e restrita a um pequeno grupo/elite de pessoas. O primeiro telejornal, intitulado de Imagens do Dia, assim como os outros programas da emissora, era transmitido ao vivo de um estúdio e tinha um curto tempo de duração. Com muitos improvisos, as notícias eram transmitidas em formato de notas secas e/ou cobertas e a figura do apresentador na bancada era central. "Ele era o principal elemento legitimador do telejornal, era ele quem mostrava o rosto e a voz, que emprestava o seu reconhecimento profissional para dar validade ao discurso das notícias" (SILVA, 2011, p. 273). Ainda de acordo com Silva (2011), as notícias eram variadas, com foco em São Paulo, mas também com presença de informações de outras partes do país.

[...] é possível inferir que as suas pautas versavam sobre assuntos de interesse geral como a cobertura de eventos culturais (Bienal de Artes e a chegada do circo), temas do quotidiano relacionados com a família (as crianças na creche e o concurso criança robusta), factos diversos (os objectos perdidos e a reforma do hidroavião Jahú), além de notícias de outros estados, como a manifestação no Maranhão (SILVA, 2011, p. 273-274).

O Imagens do Dia não duraria tanto: saiu do ar em 1951, dando lugar ao Telenotícias Panair, cujo espaço na programação seria ocupado posteriormente pelo líder de audiência Repórter Esso (1952), que, herdado do rádio, ganhou uma versão na televisão. O nome Esso

\footnotetext{
${ }^{4}$ Televisão comercial é a que depende de verbas publicitárias para se manter e que geralmente é propriedade de um grupo privado ou familia (JAMBEIRO, 2008). Outros modelos de televisão são: a pública, que é custeada pela sociedade/governo e com a divulgação de conteúdo voltado para o interesse público; e a estatal, com foco na divulgação das ações governamentais (JAMBEIRO, 2008)

5 Apesar de muitas obras considerarem o pioneirismo da TV Tupi de São Paulo na década de 1950, alguns autores, como Beghini (2013), apontam que a primeira transmissão de TV aberta no Brasil aconteceu em 1948 pelo técnico em eletrônica Olavo Bastos Freire, em Juiz de Fora, Minas Gerais. Entretanto, não havia se constituído ainda uma emissora de TV com operação regular. A transmissão teria sido pontual, com presença de público e autoridades.
} 
seria um "oferecimento" dos postos Esso, assim como o Jornal Nacional, em 1969, seria patrocinado pelo Banco Nacional. ${ }^{6}$

Esse período inicial da televisão no Brasil também é chamado de Fase Elitista (MATTOS, 1990), já que um aparelho de televisão era extremamente caro. De acordo com Mattos (1990), "nesta primeira fase a televisão caracteriza-se, principalmente, pela formação do oligopólio dos Diários Associados” (MATTOS, 1990, p. 12). Em 1951, é inaugurada a TV Tupi Rio do Janeiro e um ano depois surge a TV Paulista. Ainda na década de 1950 surgem a TV Record (São Paulo/1953), TV Rio (Rio de Janeiro/1955), TV Itacolomi (Belo Horizonte/1955) e TV Continental (Rio de Janeiro/1959) (BARBOSA, 2013).

Na década de 1960, a televisão obtém força no interior do país. Com a inauguração de Brasília, três emissoras se instalam na nova capital federal, em 1960: TV Brasília, TV Nacional e TV Alvorada (que pertencia à TV Rio). Em Recife, no mesmo ano, entram no ar a TV Rádio Clube de Pernambuco e a TV Jornal do Commercio. No sul do país, em Curitiba, surge a TV Paranaense. Cabe ainda ressaltar que em São Paulo inaugurava a TV Excelsior (que dois anos depois seria a primeira emissora a fazer emissões em cores) e a TV Cultura, essa última pertencente às Emissoras Associadas, com participação também de Assis Chateaubriand. Em 1962, surge a TV Alterosa em Minas Gerais - em funcionamento até os dias atuais - também pertencente aos Diários Associados (BARBOSA, 2013).

Algumas das emissoras regionais, como a TV Gaúcha de Porto Alegre (RS), nasciam totalmente independentes. No entanto, com o passar dos anos, era comum o movimento de afiliação às emissoras maiores. No caso da TV Gaúcha, primeiramente foi afiliada à TV Excelsior e depois à Rede Globo, em 1965. A regionalização aconteceu com maior intensidade nas regiões com maior desenvolvimento econômico. Segundo o Anuário Estatístico do Brasil do IBGE (BARBOSA, 2013, p. 308), em 1969 havia no Sudeste 21 emissoras em funcionamento; no Sul, doze, no Nordeste, oito, no Centro-Oeste, sete (parte considerável em Brasília) e, no Norte, apenas quatro.

Mesmo assim, as emissoras distantes das capitais tinham problemas para se sustentar. Uma das primeiras, a TV de Ribeirão Preto (SP), “funcionava de maneira precária, ficando até três dias fora do ar e ainda amargava prejuízos" (PEREIRA, 2005, p. 48). Um dos motivos para

\footnotetext{
${ }^{6}$ Exemplos de outros telejornais com nomes dos patrocinadores são Telejornal Brahma e Jornal Ultranotícias.
} 
o desenvolvimento tardio em regiões fora das áreas metropolitanas era a pouca quantidade de aparelhos televisores entre a população interiorana. Algumas estações conseguiram se sustentar quando eram vinculadas a grandes grupos, como a TV Coroados de Londrina. Inaugurada em 1963, teve como proprietário Chateaubriand, atraído pelos altos valores de publicidade que poderiam ser cobrados na tevê. O primeiro telejornal, Telenotícias Transparaná, tinha o estilo radiofônico, e, como outros da época, também levava o nome do patrocinador (PEREIRA, 2005, p. 49).

Assim, a mídia televisiva pode ser abordada como sinônimo de modernidade no interior, já que é comum a vinculação desse momento histórico da televisão com transformações comerciais e sociais da época, como aconteceu no norte do Paraná, visto que "a nova ferramenta da comunicação sacudiu a rede de anunciantes, deu novo dinamismo à indústria e ao comércio e mostrou à cidade o seu povo, suas crenças, festas, acontecimentos sociais, esportes, alegrias e tristezas" (PEREIRA, 2005, p. 50). Nessa linha de raciocínio, primeiro a "nova ferramenta" precisava agradar os anunciantes, para, posteriormente, mostrar seu potencial para aspectos sociais, como crenças, festas, alegrias e angústias.

Outra emissora pertencente aos Diários Associados foi a TV Mariano Procópio, de Juiz de Fora. Após o Repórter Esso, era exibido com cinco minutos de duração o Telefoto Jornal. O nome é reflexo do próprio processo de produção do noticiário, já que o informativo consistia numa espécie de projetor de slides que mostrava um resumo fotográfico dos acontecimentos da cidade (MUSSE, 2009, p. 3). Entre 1960 e 1963, a TV Mariano Procópio gravava em película um bloco de cinco minutos que era levado de ônibus até o Rio de Janeiro para ser exibido dentro do Jornal da Tupi. Em 1964, a cidade ainda contaria com a TV Industrial, que teria conseguido gerar $80 \%$ de sua programação pelos próprios estúdios (MUSSE, 2009, p. 5). A emissora também produzia o telejornal A hora é notícia, que em 1968 chegou a ter uma hora e 15 minutos de duração e 16 anunciantes diários. Segundo Musse (2009), o noticiário começava com a leitura de uma espécie de opinião editorial e depois vinham as notícias sobre sociedade, arquitetura, transporte, coluna social, horóscopo, política, esporte, arte, entre outros assuntos que envolviam o município. A emissora foi extinta em 1980 quando foi vendida para Roberto Marinho, proprietário da TV Globo. Entre os motivos, estavam o falecimento de dois sócios, o alto gasto para entrar em cadeia com outras emissoras via satélite da Embratel e o custo para 
preencher a programação, visto que tinha o hábito de comprar programas de emissoras maiores, como a TV Tupi, TV Gazeta, TV Rio e a própria TV Globo (MUSSE, 2009).

A situação da TV Industrial de Juiz de Fora demonstra dois pontos importantes que contrapõem algumas tecnologias que, normalmente, são interpretadas como sendo apenas positivas para o telejornalismo local e regional. O primeiro é a presença do satélite da Empresa Brasileira de Telecomunicações (Embratel), permitindo, no final da década de 1960, a constituição das redes com transmissão em todo o território nacional, além de facilitar a troca de programas e o ao vivo (PERUZZO, 2005). Peruzzo (2005) afirma que as redes de tevês locais e regionais comerciais só foram consolidadas com a instalação da rede de micro-ondas da Embratel, que permitia uma interação mais dinâmica entre o conteúdo produzido pelas emissoras.

É claro que a tecnologia trouxe avanços importantes e não há o que contestar sobre sua necessidade para as telecomunicações do Brasil - foi por meio dela, por exemplo, que os brasileiros puderam acompanhar a chegada do homem à lua (BARBOSA, 2013). No entanto, é preciso reconhecer que, de certa forma, prejudicou a produção local e regional. Em um primeiro momento, pelo fato de as estações locais e regionais utilizarem o satélite para exibir programas em rede que muitas vezes eram produzidos em outras localidades, perdendo, assim, o interesse em investir em conteúdo e programas próprios. E num segundo momento, como se percebe no caso da TV Industrial, pelo fato de que a tecnologia era cara e tinha um peso considerável no orçamento das emissoras menores que optavam por se organizar em rede. A TV Industrial fazia parte de uma rede menor, a Rede de Emissoras Independentes, composta pela TV Record, TV Rio e TVS. Sem conseguir se sustentar, foi "abocanhada" por outra rede maior, a Rede Globo. O exemplo demonstra, em um exercício reflexivo, que tal tecnologia, devido aos altos custos de contratação e manutenção, colaborou para o fortalecimento de quem tinha mais recursos, numa difícil e injusta disputa para as mídias local e regional, visto que um dos resultados desse processo, entre outros fatores, foi a centralização da produção noticiosa nas regiões metropolitanas brasileiras e o fortalecimento das emissoras chamadas de "cabeça de rede", de escala nacional. 
O segundo ponto que problematiza as tecnologias emergentes à época, é a respeito de outra inovação na mídia televisiva na década de 1960: o videotape. ${ }^{7}$ Peruzzo (2005) descreve que o telejornalismo local começou a obter forma no Brasil com o advento do videotape, o que possibilitou a formação das primeiras redes por meio do envio de materiais audiovisuais entre as metrópoles. No entanto, não é esclarecido se chegou a contribuir para a expansão do telejornalismo local e regional. O trabalho de Ihitz e Cunha (2017) permite um contraponto a essa percepção. Os autores focam na mídia televisiva no Rio Grande do Sul. Para isso, recorrem à revista quinzenal TV Sul Programas, que foi editada no estado e se dedicava exclusivamente à televisão, como uma forma de divulgar o então novo meio de informação e de entretenimento no decênio de 1960. Por meio de reportagens publicadas no impresso, mostram que no estado gaúcho os primeiros canais foram os locais/regionais TV Piratini e TV Gaúcha.

É dito por Ihitz e Cunha (2017, p. 10) que o uso de fitas na década de 1960 mudou a rotina produtiva dentro das TVs e interessa aqui destacar como isso transformou a cobertura local, já que "surgia ali mais um fator de competição entre as tevês para reproduzir programas produzidos no Rio de Janeiro e São Paulo". Evidencia-se, portanto, que o videotape contribuiu para diminuir a produção local, reduzindo também os custos operacionais. Alguns programas chegaram a ser extintos e até mesmo as emissoras do eixo Rio-São Paulo passaram a diminuir a produção de conteúdo, ao optarem por preencher a grade de programação com "enlatados" norte-americanos (IHITZ; CUNHA, 2017, p. 11). Portanto, reconhece-se que, além dos benefícios amplamente divulgados sobre as vantagens do uso do videotape, a tecnologia era uma forma de diminuir os custos oriundos das produções locais e regionais. No caso da TV Industrial de Juiz de Fora, por exemplo, 20\% da programação era preenchida com filmes e compras de programas de outras emissoras e redes que chegavam até a emissora por meio dos videotapes (MUSSE, 2009).

A década de 1960 ainda marca a fundação da TV Globo no Rio de Janeiro em 1965, pelo empresário Roberto Marinho. A data institui a formação do oligopólio midiático brasileiro, altamente concentrado e hegemonizado pela própria TV Globo, cuja duração persiste até hoje. Bolaño (1999) afirma que 1965 é o marco do início da distribuição nacional dos programas

\footnotetext{
${ }^{7}$ Videotape é uma fita magnética utilizada tanto para gravação de programas nos estúdios, quanto nas externas pelas câmeras. Atualmente seu uso tem sido substituído por discos rígidos e cartões de memoria.
} 
feitos no Rio de Janeiro e São Paulo, devido ao videotape. A inauguração do Jornal Nacional, exibida em rede para todo o território nacional em 01 de setembro de 1969, é outro acontecimento importante. O período entre 1965 e 1969

[...] deve ser definido como um período de transição de um sistema organizado sobre mercados locais concorrenciais, com barreiras à entrada extremamente frágeis e situações de liderança precárias, para um sistema oligopolista, nacionalmente integrado, hierarquizado, estável e fortemente dominado pela empresa líder, a Rede Globo de Televisão (BOLAÑO, 1999, p. 19).

Em 1966 a TV Globo se torna líder de audiência com 45\% de participação, uma posição que nunca mais é desbancada. O fortalecimento da emissora, com respaldo de recursos estrangeiros, principalmente da empresa norte-americana Time Life, e apoio político do regime militar, não só impediu uma pluralização do meio televisivo no país, mas também o desenvolvimento de forma efetiva de outras emissoras com diferentes modelos de gestão, como a pública (DINIZ, 2013).

Em 1967 o governo militar criava, via Decreto-Lei no. 236 que modificava o Código Brasileiro de Telecomunicações de 1962, a Televisão Educativa: emissoras dedicadas à divulgação de programas educacionais. Essas emissoras deveriam ser implementadas por universidades e fundações com o intuito de transmitir aulas, conferências, palestras e debates (LOPES, 2010), tendo também grande potencial de regionalizar a televisão, já que, com menos burocracica para obter a concessão, seria possível levar a mídia a lugares de menor interesse comercial, como o interior do país. A TV Universitária de Pernambuco (1968), emissora educativa, é considerada a primeira emissora pública brasileira. No entanto, a realidade foi diferente: a forma como o governo queria desenvolver a programação educativa foi bastante criticada por pedagogos (LOPES, 2010) e o investimento público não foi o suficiente para desenvolver essas emissoras a ponto de competir com as tevês comerciais. Aliás, enquanto as televisões educativas e públicas careciam de recursos, o governo militar, utilizando-se de estruturas educacionais públicas, investia em programas da TV Globo, como o Projeto Global de Teleducação, da Fundação Roberto Marinho em parceria com a Universidade de Brasília (DINIZ, 2013). 


\section{Fase 2 (1970-1990): o regional na grade de programação}

A segunda fase refere-se à popularização de programas com foco regional. A década de 1970 destaca-se pelas produções de novelas e de shows de auditório (MATTOS, 1990). O início da década de 1980 é marcado pela falência e encerramento das emissões da TV Tupi. Por outro lado, surgem duas novas emissoras de atuação nacional: a Manchete, em 1981, e o Sistema Brasileiro de Televisão (SBT, em 1983. É nessa época que a mídia hegemônica comercial começava a investir no jornalismo local e regional de suas redes. Em 02 de abril de 1979 foi ao ar pela Rede Globo o Jornal das Sete (Figura 1), um telejornal com 15 minutos de duração veiculado em cada capital no início ou no fim do Jornal Nacional.

Em determinado ponto do noticiário, sem que o telespectador percebesse, desfazia-se a rede e cada estado entrava com o seu noticiário local. O tempo para desenvolver as matérias, porém, era escasso, o que implicava em um rigor excessivo em relação ao noticiário. A cobertura acabava se restringindo a notícias curtas de 30 segundos sobre problemas de água, esgoto e calçamento (JORNAL, s.d., não paginado)

Identifica-se que a Globo vincula o jornalismo local às notícias que considera como sendo de serviço, "sobre problemas de água, esgoto e calçamento" (JORNAL..., s.d., não paginado).

Figura 01 - Logo do Jornal das Sete, veiculado até 1983

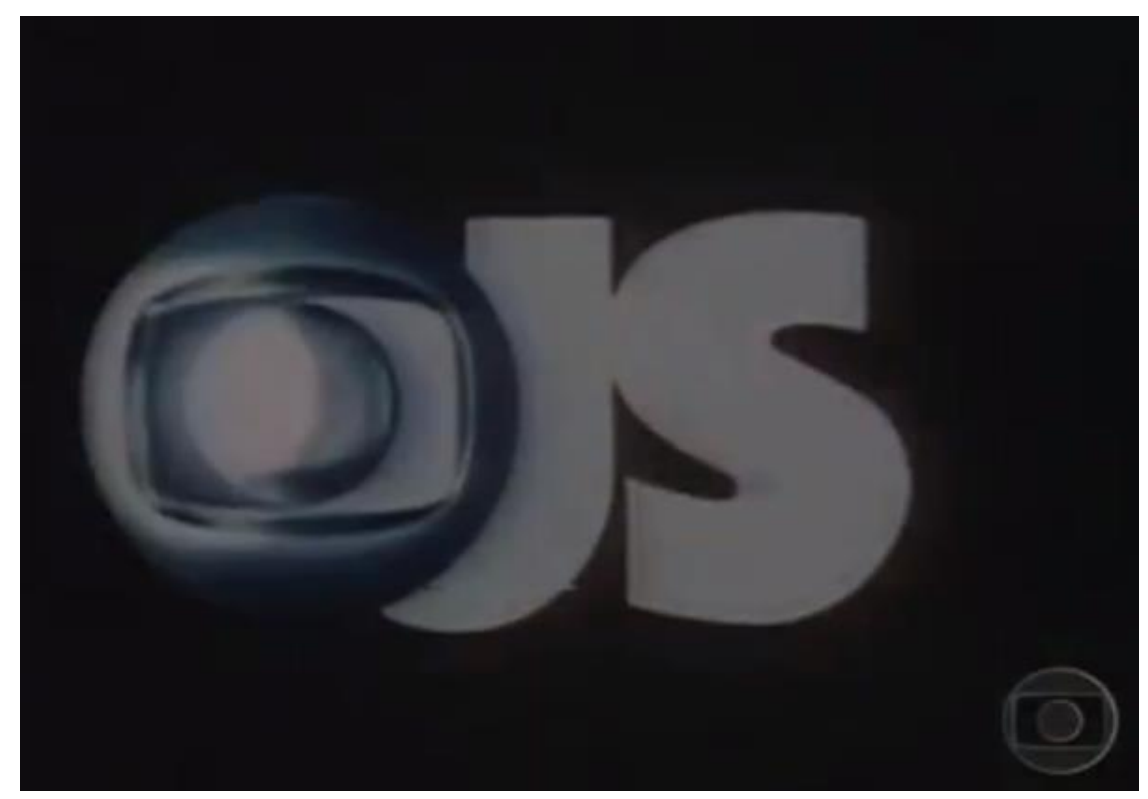

Fonte: Jornal... (s.d.). 
O Jornal das Sete foi substituído em 01 de janeiro de 1983 pelos Praça TV, ${ }^{8}$ no ar até hoje na grade da emissora e de suas afiliadas, além do Bom Dia Brasil, que também passou a ser produzido em sua versão local em algumas afiliadas em anos posteriores. Até 1989, os Praça TV tinham três edições diárias de segunda à sábado: uma na faixa das 12 horas, outra às 19 horas e uma última, após o Jornal da Globo - esta atualizava as notícias que eram exibidas no Praça 2 da faixa das 19 horas e um bloco era dedicado às colunas de esporte, política, economia e cultura (RJTV, s.d.). Segundo a Globo, o objetivo dos Praça TV era de "conferir maior identidade ao noticiário regional, até então incorporado aos telejornais Hoje, Jornal Nacional e Jornal da Globo" (RJTV, s.d.). A terceira edição dos Praça TV foi extinta em março de 1989. $\mathrm{Na}$ época, o provável motivo foi a concorrência com o programa Jô Soares Onzes e Meia, conforme uma nota publicada no então Jornal do Brasil (CEZIMBRA, 1989).

A primeira edição, veiculada inicialmente às 12h40, também foi suspensa em 1989, mas voltou ao ar em 1992, sendo exibida antes do Jornal Hoje. Em 1999, o Praça 1 teve seu tempo ampliado para 50 minutos de duração, e a Globo anunciou uma nova proposta para o telejornal. No caso do então $R J T V$, disse que "ganhou um perfil comunitário. Para se aproximar da população do Rio de Janeiro, o jornal ficou mais dinâmico. Cresceu o número de entradas ao vivo dos repórteres e das entrevistas no estúdio" (RJTV, s.d. ). É importante fazer uma ressalva nesse ponto em que a emissora se autointitula como promotora de um "jornalismo comunitário". É recorrente o discurso jornalístico de um programa informativo local denominar-se como sendo comunitário pelo fato de oferecer um noticiário de serviços, sendo as pautas focadas em assuntos como trânsito, variação de preços, receitas, empregos, entre outros. No entanto, é preciso compreender toda a carga conceitual que o termo envolve e que falar de jornalismo comunitário também perpassa pelo próprio modelo de negócio da organização e por quem está à frente dos processos que envolvem o jornalismo (DORNELLES, 2008).

O sistema de afiliação brasileiro condiciona um engessamento na grade das emissoras locais e regionais para pertencerem à rede. Enquanto nos Estados Unidos as estações têm liberdade para montar a grade de programação com a possibilidade de negociar compras de

\footnotetext{
${ }^{8}$ Praça TV refere-se aos telejornais locais/regionais produzidos pela TV Globo e suas afiliadas, como o MG1, RJ2, SP1, entre outros.
} 
programas diretamente com as produtoras. ${ }^{9}$ sendo obrigadas a exibir apenas determinados programas da matriz, no Brasil a realidade é diferente: as afiliadas, sejam elas do SBT, RecordTV, Band e da TV Globo, precisam seguir regras estabelecidas pelas matrizes que limitam suas autonomias. É uma herança de um regime político controlador que se estende para a mídia televisiva, já que "o sistema de redes foi criado durante a ditadura militar, para melhor poder controlar os conteúdos" (ABRANTES, 2004, p. 8).

Assim, a quantidade de jornais e o tempo de duração dos programas locais e regionais são os mesmos em todas as estações que compõem a rede de afiliadas, sendo poucas as variações. A produção local e regional geralmente é focada no jornalismo e, mesmo assim, com pouco espaço na grade, não ultrapassando, na maioria das afiliadas, $15 \%$ da programação diária. Assim, constata-se que são poucos os casos de formatos diferenciados de programas, como talkshows e debates; esses somente ganham a versão local/regional na época das eleições.

Na década de 1990 surge a tendência da segmentação da televisão, principalmente com a estreia do canal da MTV brasileira (1990), além da chegada da tevê por assinatura. Presente nas tecnologias via cabo e satélite, as tevês por assinatura concentram a maior quantidade de assinantes nas regiões mais fortes economicamente. No topo do total de assinaturas, conforme dados da Anatel de 2017, estão os estados de São Paulo, Rio de Janeiro, Minas Gerais, Rio Grande do Sul e Paraná (TV..., 2018), o que demonstra uma desigualdade econômico-social no acesso à tevê paga e a concentração na região sul-sudeste - inclusive de emissoras e de produção dos programas, já que muitas fazem parte do sistema GloboSat, ${ }^{10}$ como Multishow, GNT e SporTV. Em 1996 surgem os canais allnews, acompanhando a tendência do rádio com emissoras 24 horas dedicadas às notícias. A primeira foi a Globo News, disponibilizada via operadora de televisão por assinatura em 1996 e, na década de 2000, os canais abertos Band News, em 2001, e Record News, em 2007. Apesar de frequentemente veicularem notícias do interior do país, inclusive com entradas ao vivo nos principais telejornais, constata-se que os estúdios são restritos ao eixo Rio-São Paulo-Brasília.

\footnotetext{
${ }^{9}$ Por meio de um modelo denominado Syndication, os canais locais e regionais dos Estados Unidos são livres para negociar diretamente com as produtoras a compra de programas, como talkshows, informativos e séries ficcionais ${ }^{10}$ A GloboSat pertence ao Grupo Globo, tendo sido criada em 1991 e com início de suas operações focadas na TV por assinaturas.
} 
No final da década de 1990, Bolaño (1999) acreditava que a segmentação da televisão e a ascensão do SBT e da Record, principalmente com o investimento em produções populares e em programas produzidos no México, no caso do SBT, poderiam ameaçar de certa forma a hegemonia da Rede Globo ou mesmo afetar o seu "padrão de qualidade", que, conforme cita Cannito (2010), ao longo dos anos mostrou-se apenas como técnica. No entanto, o que emergiu na primeira e na segunda décadas dos anos 2000 foi uma competição pelo segundo lugar da audiência, em que a RecordTV ultrapassou o SBT por vários anos, graças aos recursos oriundos da Igreja Universal, que permitiram o investimento em novelas, jornalismo e contratações de artistas e jornalistas da Globo e do próprio SBT. A TV Globo permanece como a líder isolada de audiência. É curioso que entre as cinco maiores audiências da TV Globo, frequentemente apareça o regional Praça 2, exibido na faixa das 19 horas. ${ }^{11}$

\section{Fase 3 (2000-2019): a tevê no século XXI}

A década de 2000 marcou três transformações no cenário televisivo brasileiro: em 2006 o Governo Federal publicou os parâmetros para transição da tevê analógica para a tevê digital no país, que teria a primeira transmissão em dezembro de 2007, em São Paulo. Um aspecto do Sistema Brasileiro de Televisão Digital que poderia incrementar a segmentação da televisão no Brasil é a possibilidade da multiprogramação, que "possibilita a transmissão de programações distintas em um mesmo canal de TV digital aberta. Ou seja, no mesmo horário, o telespectador pode assistir a diferentes programas em um único canal" (MULTIPROGRAMAÇÃO, 2009, não paginado). Apesar da promessa, e por uma questão legal, atualmente o recurso é disponibilizado apenas para emissoras públicas. Em São Paulo, quatro emissoras dividem o mesmo canal: TV Brasil SP (1.1), TV Brasil (1.2), TV Escola (1.3) e Canal Saúde (1.4). As emissoras privadas não fazem uso dessa tecnologia e apenas transmitem suas programações em alta definição. Em relação às possibilidades para o telejornalismo local e regional, a multiprogramação poderia ser uma estratégia para gerar canais exclusivos para veiculação de notícias/programas locais e regionais sem afetar a grade nacional exibida pela rede em seus canais principais - algo ainda distante, considerando o interesse das grandes emissoras

\footnotetext{
${ }^{11}$ Entre os dias 12 e 18 de março de 2018, por exemplo, o Praça TV $2^{\text {a }}$ Edição foi o terceiro programa de maior audiência do Brasil, segundo o Ibope (ALMEIDA, 2018).
} 
comerciais apenas na transmissão em alta definição. Por outro lado, em algumas cidades do interior, há emissoras públicas locais que aproveitam esse sistema para divulgarem conteúdo. É o caso da JFTV Câmara, canal de tevê da Câmara Municipal de Juiz de Fora, em Minas Gerais (SILVA, 2020).

O segundo grande acontecimento da década de 2000 foi a tentativa do Governo Lula em desenvolver a comunicação pública com a criação da Empresa Brasil de Comunicação (EBC), que iniciou em dezembro de 2007 a emissão da TV Brasil, emissora pública brasileira. A Lei no. 11.652, de 7 de abril de 2008, que instituiu os objetivos dos serviços de radiodifusão pública explorados pelo Poder Executivo, descreve entre as obrigações do órgão, no art. $2^{\circ}$, a "promoção da cultura nacional, estímulo à produção regional e à produção independente" (BRASIL, 2008). $\mathrm{O}$ incentivo à produção regional se refletiu na própria composição das matrizes da TV Brasil/EBC, sendo uma das sedes localizadas em São Luís, no estado do Maranhão, nordeste do país. As demais sedes ficaram em Brasília (central), São Paulo e Rio de Janeiro. Porém, a nova emissora enfrentou diversos problemas no que tange a sua manutenção, como críticas em relação aos índices de audiência e a vulnerabilidade relativa à influência governamental no conteúdo/políticas da emissora.

A tentativa de integrar as emissoras regionais e locais para fomentar o noticiário diário Repórter Brasil também não foi bem-sucedida. Em entrevista concedida ao autor deste trabalho em 2015, a então diretora de jornalismo, Nereide Beirão, afirmou que, entre todas as afiliadas da TV Brasil, apenas a Rede Minas (Minas Gerais) conseguia enviar com regularidade material de qualidade (BEIRÃO, 2015). ${ }^{12}$ De uma forma geral, na grade de programação, segundo o Plano de Trabalho 2013 da EBC, as emissoras parceiras produziram 10\% da grade da TV Brasil. No caso do Repórter Brasil, no primeiro semestre de 2013, de todas as matérias veiculadas, apenas 5\% foram enviadas por parceiros. A necessidade de capacitação das equipes locais foi apontada como o grande entrave para aumentar esse número (BRASIL, 2013, p. 17-18). Em 2019, durante o governo de Jair Bolsonaro, o canal estatal NBR foi fundido com a TV Brasil, minando seu caráter público, e a sede de São Luís foi extinta.

\footnotetext{
12 BEIRÃO, Nereide. Nereide Beirão: entrevista [18 mar. 2015]. Entrevistador: José Tarcísio Oliveira Filho. Brasília, DF, 2015. Arquivo .mp3.
} 
A terceira transformação foi a popularização da internet e dos dispositivos móveis, convocando a mídia televisiva ao ambiente da convergência midiática. Assistir à televisão não seria mais exclusividade de um único aparelho: a possibilidade de ver tevê foi expandida para smartphones, tablets e computadores/notebooks, surgindo o fenômeno da segunda tela (EMERIM; FINGER; COUTINHO, 2018). A melhoria da banda larga também faz surgir o sistema de video on demand, em que o telespectador tem a opção de assistir ao conteúdo no tempo/dispositivo que preferir. Exemplos desse novo serviço de streaming que envolve a disponibilização de conteúdo jornalístico, inclusive os locais (de maneira tímida), são o Globo Play da TV Globo, iniciado em 2015; o Play Plus da RecordTV, em 2018; e o SBT Vídeos do SBT, em 2020. Nesse contexto, o telespectador também passa a produzir conteúdo e participar mais dos telejornais.

\section{Considerações finais}

Em vias de conclusão, elencam-se duas considerações complementares ao exercício de periodização histórica da tevê regional no Brasil. A primeira é relativa às concentrações políticas e econômicas da mídia televisiva regional. Aguiar (2016), num estudo sobre as escalas geográficas e a concentração midiática regional, demonstra que muitos veículos de comunicação estão nas mãos de grupos empresariais regionais. É o caso da Rede Brasil Sul de Comunicação (RBS), proprietária de 18 emissoras de tevês abertas nos estados do Rio Grande do Sul e Santa Catarina, e da TV Tribuna (afiliada SBT no Espírito Santo), pertencente ao Grupo Industrial João Santos, cujo carro-chefe é o Cimento Nassau (AGUIAR, 2016).

Esse contexto põe em evidência a dicotomia entre a atividade econômica e o compromisso com a comunicação regional. Questiona-se até onde a radiodifusão televisiva local/regional é independente e destinada a cumprir um papel de serviço público voltado para o desenvolvimento local. O estabelecimento do sistema de afiliadas intensifica a complexidade desse problema, diante da pouca flexibilidade para adequar os informativos (e demais subgêneros televisivos) à realidade regional. A abordagem histórica da mídia televisiva regional auxilia a compreender o cenário contemporâneo, ao mesmo tempo em que demonstra, até certo ponto, como as políticas públicas foram ineficazes ao longo das décadas no sentido de garantir uma comunicação regional mais diversa na realidade brasileira. 
Um segundo ponto de reflexão é acerca da própria proposta do trabalho em realizar uma sistematização da história da televisão regional, com ênfase nos programas jornalísticos. O percurso teórico tem sua originalidade em propor um recorte histórico da mídia televisiva de escalas locais e regionais, portanto, difere-se de outros estudos que também periodizam a televisão, mas com outras abordagens, como a partir da economia política da televisão, como fazem Mattos (1990) e Bolaño (1999).

\section{Referências}

ABRANTES, Marta. Geografia da indústria audiovisual no Brasil. In: CONGRESSO BRASILEIRO DE CIÊNCIAS DA COMUNICAÇÃO, 27., 2004, Porto Alegre. Anais [...]. São Paulo: Intercom, $2004 . \quad$ Disponível em: http://www.portcom.intercom.org.br/pdfs/71551013738331782542262269074986664929.pdf. Acesso em: 25 abr. 2020.

AGUIAR, Sônia. Territórios do jornalismo: geografias da mídia local e regional no Brasil. Petrópolis: Vozes, Editora PUCRio, 2016.

ALMEIDA, João. Veja as 10 maiores audiências de cada emissora no Brasil; Apocalipse perde para reprise mexicana. TV Foco. 23 mar. 2018. Disponível em: https://www.otvfoco.com.br/veja-as-10-maiores-audiencias-de-cada-emissora-no-brasilapocalipse-perde-para-reprise-mexicana/. Acesso em: 27 abr. 2020.

BARBOSA, Marialva. História da comunicação no Brasil. Petrópolis: Vozes, 2013.

BEGHINI, Ricardo. A pré-história da TV no Brasil. In: ENCONTRO NACIONAL DE HISTÓRIA DA MÍDIA, 9., 2013, Ouro Preto. Anais [...]. Porto Alegre: Alcar, 2013. Disponível em: http://www.ufrgs.br/alcar/encontros-nacionais-1/9o-encontro-2013/artigos/gt-historia-damidia-audiovisual-e-visual/a-pre-historia-da-tv-no-brasil. Acesso em: 25 abr. 2020.

BEIRÃO, Nereide. Nereide Beirão: entrevista [18 mar. 2015]. Entrevistador: José Tarcísio Oliveira Filho. Brasília, DF, 2015. Arquivo .mp3.

BOLAÑO, César. A economia política da televisão brasileira. Revista Brasileira de Ciências da Comunicação, São Paulo, v. 22, n. 2, p. 15-32, 1999. Disponível em: http://portcom.intercom.org.br/revistas/index.php/revistaintercom/article/view/998/901. Acesso em: 25 abr. 2020.

BRASIL. Lei no. 11.652, de 7 de abril de 2008. Institui os princípios e objetivos dos serviços de radiodifusão pública... Disponível em: http://www.planalto.gov.br/ccivil_03/_ato20072010/2008/lei/111652.htm. Acesso em: 08 set. 2019. 
BRASIL por inteiro. Revista do Conselho Curador da EBC, Brasília, n. 1, p. 16-21, 2013. Disponível em: http://issuu.com/03978/docs/revista_conselho_curador_v2. Acesso em: 28 maio 2020.

BRASIL. Presidência da República. Secretaria Especial de Comunicação Social. Pesquisa brasileira de mídia 2016 : hábitos de consumo de mídia pela população brasileira. Brasília : Secom, 2016.

CANNITO, Newton Guimarães. A televisão na era digital: interatividade, convergência e novos modelos de negócio. São Paulo: Summus, 2010.

CEZIMBRA, Márcia. Boni modifica os telejornais. Jornal do Brasil, Rio de Janeiro, 04 jan. $1989 . \quad$ Disponível em: http://www.tv-pesquisa.com.pucrio.br/mostraregistro.asp?CodRegistro=8617\&PageNo=1. Acesso em: 17 ago. 2018.

DINIZ, Ângela Maria Carrato. Uma história da TV pública brasileira. 2013. Tese (Doutorado em Comunicação e Sociedade) - Programa de Pós-Graduação em Comunicação, UnB, Brasília, 2013. Disponível em: http://repositorio.unb.br/handle/10482/15462. Acesso em: 20 abr. 2020.

DORNELLES, Beatriz. Características do jornalismo impresso local e suas interfaces com jornais comunitário. Comunicação \& Inovação, São Caetano do Sul, v. 9, n. 16, p. 23-31, 2008.

EMERIM, Cárlida; FINGER; Cristiane; COUTINHO; Iluska (org.). Estudos contemporâneos em telejornalismo: narrativas de jornalismo para telas. Florianópolis: Insular, 2018.

IHITZ, Greetchen Ferreira; CUNHA, Ricardo Ramos Carneiro da. TV Sul Programas: fragmentos sobre a história da televisão no Rio Grande do Sul. In: CONGRESSO BRASILEIRO DE CIÊNCIAS DA COMUNICAÇÃO, 40,, 2017, Curitiba. Anais [...] São Paulo: $\quad 2017 . \quad$ Intercom, Disponível em: https://portalintercom.org.br/anais/nacional2017/resumos/R12-0895-1.pdf. Acesso em: 17 abr. 2020.

JAMBEIRO, Othon. A regulação da TV no Brasil: 75 anos depois, o que temos? Estudos de Sociologia, Araraquara, v. 13, n. 24, p. 85-104, 2008. Disponível em: https://periodicos.fclar.unesp.br/estudos/article/view/867. Acesso em: 25 abr. 2020.

JORNAL das Sete. Memória Globo, s.d. Disponível em: www.memoriaglobo.globo.com/programas/jornalismo/telejornais/jornal-das-sete.htm. Acesso em: 29 ago. 2019.

LEAL FILHO, Laurindo. A melhor TV do mundo: o modelo britânico de televisão. São Paulo: Summus Editorial, 1997. 
LOPES, Ivonete da Silva. TVs Educativas catarinenes: relações entre política, mercado e sociedade civil. 2010. Dissertação (Mestrado em Comunicação) - Programa de Pós-Graduação de Comunicação, Universidade Federal Fluminense, Niterói, 2010. Disponível em: http://est.uff.br/wp-

content/uploads/sites/200/2020/03/tese_mestrado_2010_ivonete_da_silva_lopes.pdf. Acesso em: 26 abr. 2020.

MATTOS, Sérgio. Um perfil da TV brasileira. Salvador: A Tarde, 1990.

MULTIPROGRAMAÇÃO. DTV. Site Oficial da TV Digital Brasileira, s.d., Brasília. Disponível em: https://dtv.org.br/portfolio_page/multiprogramacao/\#: :text=Multiprograma\%C3\%A7\%C3\% A3o\%20\%C3\% A9\%20um\%20recurso\%20da,programas\%20em\%20um\%20\%C3\%BAnico\% 20canal. Acesso em: 24 dez. 2021.

MUSSE, Christina. A hora é notícia: reflexões sobre o telejornalismo mineiro na década de 60. In: ENCONTRO NACIONAL DE HISTÓRIA DA MÍDIA, 7., 2009, Fortaleza. Anais [...]. Porto Alegre: Alcar, 2009. Disponível em: http://www.ufrgs.br/alcar/encontros-nacionais$1 /$ encontros-nacionais/7o-encontro-2009-

1/A\%20hora\%20e\%20noticia\%20reflexoes\%20sobre\%20o\%20telejornalismo\%20mineiro.pd f. Acesso em: 25 abr. 2020.

OLIVEIRA FILHO, José Tarcísio. Proximidade no telejornalismo local e regional: uma proposta de sistematização. Revista Fronteiras, Porto Alegre, v. 21, n. 2, p. 102-115, maio/ago. 2019.

em: http://revistas.unisinos.br/index.php/fronteiras/article/view/fem.2019.212.10/60747261.

Acesso em: 20 mar. 2020.

PEREIRA, Milton Antunes. Televisão e jornalismo: a história do telejornalismo no Norte do Paraná. UNOPAR Científica, Londrina, v. 6, n. 1, p. 47-51, jun. 2005. Disponível em: https://revistaensinoeeducacao.pgsskroton.com.br/article/view/1095/1048. Acesso em: 20 mar. 2020.

PERUZZO, Cicilia. Mídia regional e local: aspectos conceituais e tendências. Comunicação \& Sociedade, São Bernardo do Campo, v. 26, n. 43, p. 67-84, 2005. Disponível em: https://www.metodista.br/revistas/revistas-metodista/index.php/CSO/article/view/8637/6170.

Acesso em: 20 abr. 2020.

PICCININ, Fabiana. Notícias na Tv global: Diferenças ou não entre o telejornalismo americano e europeu. In: CONGRESSO BRASILEIRO DE CIÊNCIAS DA COMUNICAÇÃO, 26., 2004, Porto Alegre. Anais [...]. São Paulo: Intercom, 2004. Disponível em: http://www.portcom.intercom.org.br/pdfs/46030999987498783654979767749024369521.pdf. Acesso em: 18 abr. 2020. 
RJTV.

Memória

Globo,

s.d.

Disponível

em:

https://memoriaglobo.globo.com/jornalismo/jornalismo-e-telejornais/rjtv/estreia/6197040/.

Acesso em: 24 mar. 2020.

SILVA, Edna. Nas imagens da memória: a influência do cinejornalismo e da rádio na primeira fase do telejornalismo brasileiro. In: MARTINS, Moisés; CABECINHAS, Rosa; MACEDO, Lurdes (org.). Anuário Internacional de Comunicação Lusófona. Minho: Grácio Editores, 2011, p. 263-274.

SILVA, Helena. O papel das TVs Públicas no contexto da pandemia de Covid-19: análise noticiosa da JFTV Câmara. In: CORDEIRO, Douglas; CASSIANO, Kátia; SANTOS, Andrea; SILVA, Núbia (org.). Mídias, Informação e Ciência de Dados: pesquisas, tendências e interfaces. Goiânia: Cegraf UFG, 2020. p. 237-251.

TV por assinatura apresenta queda de 5\% no ano de 2017. Agência Nacional de Telecomunicações, Brasília, s.p., 22 fev. 2018. Disponível em: https://www.gov.br/anatel/pt$\mathrm{br} /$ assuntos/noticias/tv-por-assinatura-apresenta-queda-de-5-no-ano-de-2017. Acesso em: 26 abr. 2020 .

Submetido em: 28.06.2020.

Aprovado em: 19.12.2021. 